\title{
To create or pull from the shelf?
}

\author{
Yoshio Ootaki, MD, PhD, ${ }^{a}$ and Derek A. Williams, $\mathrm{DO}^{\mathrm{b}}$
}

From the Divisions of a Cardiothoracic Surgery and ${ }^{\mathrm{b}}$ Pediatric Cardiology, Wake Forest Baptist Health, WinstonSalem, NC.

Disclosures: Authors have nothing to disclose with regard to commercial support.

Received for publication Jan 16, 2018; accepted for publication Jan 29, 2018; available ahead of print Feb 24, 2018.

Address for reprints: Yoshio Ootaki (Otaki), MD, PhD, Medical Center Boulevard, Winston-Salem, NC 27157

(E-mail: yotaki@wakehealth.edu).

J Thorac Cardiovasc Surg 2018;155:2092-3

$0022-5223 / \$ 36.00$

Copyright (C) 2018 by The American Association for Thoracic Surgery

https://doi.org/10.1016/j.jtcvs.2018.01.048

Currently, multiple surgical options are available for pulmonary valve replacement (PVR), including autologous pericardium, mechanical valves, allografts, and bioprosthetic valves (both as stented and freestyle porcine valves and as bovine jugular vein conduits). More recently, there is growing enthusiasm for percutaneously inserted bioprosthetic valves. Longevity of the various valves is dependent on the type of conduit and the age and size of the patient at implantation.

Expanded polytetrafluoroethylene (ePTFE) has been reportedly used for PVR with monocuspid, ${ }^{1}$ bileaflet, ${ }^{2}$ and tricuspid $^{3}$ valves. The ePTFE valved conduit has shown particular promise as a preeminent valve in children and adolescents, particularly in Japan. ${ }^{4}$ Freedoms from reoperation were $100 \%$ at 5 years and $95.4 \%$ at 10 years. The follow-up now exceeds 15 years, with excellent results. The ePTFE valved conduit has been used in several centers in the United States, and freedom from reoperation after implantation of the ePTFE valved conduit seems to be better than historical data for homograft implantation. ${ }^{2,5-7}$

Smaller ePTFE valved conduits are still challenging. In this issue of the Journal, Mercer and associates ${ }^{8}$ report a retrospective study after implantation of bicuspid valved PTFE conduits and homograft conduit in patients younger than 2 years. The performance of bicuspid valved PTFE conduits was comparable to that of homografts in this study. The incidences of conduit explantation at 5 years were $55 \%$ for PTFE conduits and 56\% for homografts. Mercer and associates $^{8}$ emphasize that low cost, availability, ease of construction, and lack of potential allosensitization make valved PTFE conduits an appealing alternative to homograft conduits. They concede that both a trileaflet valve and upsizing, when feasible, are best. Yamashita and associates $^{9}$ reported a retrospective study after implantation of tricuspid valved PTFE conduits smaller than $16 \mathrm{~mm}$. The incidences of conduit replacement and conduit reintervention at 5 years were only $10 \%$ and $23 \%$, respectively. Although the patients' backgrounds were different in these two studies, the design of the valved conduit (eg, bicuspid

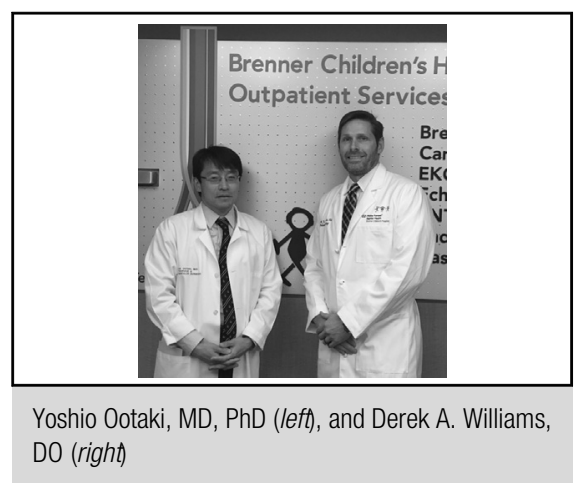

\section{Central Message}

Polytetrafluoroethylene valved conduit is a variable option for pulmonary valve replacement.

See Article page 2082.

vs tricuspid) was likely an important factor for long-term valve function.

Transcatheter PVR has emerged as a variable alternative to surgical PVR in patients with right ventricular outflow tract dysfunction. Medium-term outcomes are available now, and 5-year freedom from reintervention seems to be slightly lower than for surgical PVR in the adult population. ${ }^{10}$ The Melody transcatheter pulmonary valve (Medtronic, Inc, Minneapolis, Minn) and more recently the SAPIEN XT (Edwards Lifesciences, Irvine, Calif) are marketed for failing conduits $16 \mathrm{~mm}$ or larger at the time of surgical placement. Implantation has also been performed with conduits smaller than $16 \mathrm{~mm},{ }^{11}$ however, as well as native outflow tracts. Further device development is likely to change patient selection and long-term outcomes significantly, especially in the pediatric population.

To date, there is no "perfect" valve for providing a permanent solution in the pulmonary position. Currently, surgical PVR followed by transcatheter pulmonary valve replacement is the preferred option to limit future surgical intervention.

\section{References}

1. Turrentine MW, McCarthy RP, Vijay P, McConnell KW, Brown JW. PTFE monocusp valve reconstruction of the right ventricular outflow tract. Ann Thorac Surg. 2002;73:871-9; discussion 879-80.

2. Quintessenza JA, Jacobs JP, Morell VO, Giroud JM, Boucek RJ. Initial experience with a bicuspid polytetrafluoroethylene pulmonary valve in 41 children and adults: a new option for right ventricular outflow tract reconstruction. Ann Thorac Surg. 2005;79:924-31.

3. Yamagishi M, Kurosawa H, Nomura K, Kitamura N. Fan-shaped expanded polytetrafluoroethylene valve in the pulmonary position. J Cardiovasc Surg (Torino). 2002;43:779-86. 
4. Miyazaki T, Yamagishi M, Maeda Y, Yamamoto Y, Taniguchi S, Sasaki Y, et al. Expanded polytetrafluoroethylene conduits and patches with bulging sinuses and fan-shaped valves in right ventricular outflow tract reconstruction: multicenter study in Japan. J Thorac Cardiovasc Surg. 2011;142: 1122-9.

5. Yoshida M, Wearden PD, Dur O, Pekkan K, Morell VO. Right ventricular outflow tract reconstruction with bicuspid valved polytetrafluoroethylene conduit. Ann Thorac Surg. 2011;91:1235-8; discussion 1239.

6. Shinkawa T, Tang X, Gossett JM, Mustafa T, Hategekimana F, Watanabe F, et al. Valved polytetrafluoroethylene conduits for right ventricular outflow tract reconstruction. Ann Thorac Surg. 2015;100:129-37; discussion 137.

7. Ootaki Y, Welch AS, Walsh MJ, Quartermain MD, Williams DA, Ungerleider RM. Medium-term outcomes after implantation of expanded polytetrafluoroethylene valved conduit. Ann Thorac Surg. 2018;105:843-50.
8. Mercer CW, West SC, Sharma MS, Yoshida M, Morell VO. Polytetrafluoroethylene conduits versus homografts for right ventricular outflow tract reconstruction in infants and young children: an institutional experience. J Thorac Cardiovasc Surg. 2018;155:2082-91.

9. Yamashita E, Yamagishi M, Miyazaki T, Maeda Y, Yamamoto Y, Kato N, et al. Smaller-sized expanded polytetrafluoroethylene conduits with a fan-shaped valve and bulging sinuses for right ventricular outflow tract reconstruction. Ann Thorac Surg. 2016;102:1336-44.

10. Salavitabar A, Flynn P, Holzer RJ. Transcatheter pulmonary valve implantation: valve technology and procedural outcome. Curr Opin Cardiol. 2017;32: 655-62.

11. Martin MH, Shahanavaz S, Peng LF, Asnes JD, Riley M, Hellenbrand WE, et al. Percutaneous transcatheter pulmonary valve replacement in children weighing less than 20 kg. Catheter Cardiovasc Interv. 2018;91:485-94. 